\title{
O Público Potencial Escolar do Museu da Vida: um estudo exploratório em escolas da zona norte da cidade do Rio de Janeiro
}

\author{
The Potential Public of the Museum of Life: an exploratory study in \\ schools in the northern part of the city of Rio de Janeiro
}

\section{Eliza da Cunha Cabral ${ }^{1}$}

Vanessa Fernandes Guimarães ${ }^{2}$

\footnotetext{
${ }^{1}$ Fundação Oswaldo Cruz (Fiocruz), Casa de Oswaldo Cruz, Rio de Janeiro, RJ, Brasil. ${ }^{2}$ Fundação Oswaldo Cruz (Fiocruz), Museu da Vida, Rio de Janeiro, RJ, Brasil.

Autora correspondente: vanessa.guimaraes@fiocruz.br
}

Resumo: O presente estudo teve como objetivo investigar por que as escolas públicas municipais, situadas em bairros próximos, ainda não haviam visitado o Museu da Vida. Para tal, foram selecionadas 14 escolas públicas que nunca haviam visitado o Museu. O instrumento de pesquisa utilizado foi um questionário semiestruturado, aplicado pela pesquisadora aos profissionais da equipe diretiva, professores de ciências e coordenadores pedagógicos. Os resultados indicaram que esses profissionais têm o hábito de frequentar museus com suas escolas e famílias e se dedicam também a outras práticas culturais, como ler e ir ao teatro. Reconhecem a importância e o valor dessas atividades tanto para si, como para seus alunos. Porém, outros fatores externos influenciam o processo decisório. As principais dificuldades relatadas pelas escolas para a realização de atividades complementares no espaço extraescolar são a falta de transporte, verba reduzida e a violência urbana.

Palavras-chave: Divulgação científica; Museus de ciência; Educação não-formal. Escola pública.

Abstract: The present study aimed to investigate the reasons why the municipal public schools, located in nearby quarters, had not yet visited the Museum of Life. To that end, 14 public schools that had never visited the Museum were selected. The research instrument was a semi-structured questionnaire, administered by the researcher to the professionals in the management team, science teachers and pedagogical coordinators. The results indicated that these professionals have the habit of attending museums with their schools and families and that they also dedicate themselves to other cultural practices, like reading and going to the theater. They recognize the importance and value of these activities for themselves and their students. However, other external factors influence the decision-making process. The main difficulties reported by schools in carrying out complementary activities in the out-ofschool environment are lack of transportation, limited budget and urban violence. school.

Keywords: Science communication; Science museums; Non-formal education; Public

Recebido em: 09/09/2019

Aprovado em: 22/06/2020 


\section{Introdução}

Durante muito tempo, acreditou-se que a aprendizagem de ciências ocorria exclusivamente por meio da educação formal no contexto escolar. Embora a escola seja extremamente importante para a aquisição de competências, a aprendizagem acontece durante toda a vida do indivíduo e não é exclusiva do processo de escolarização. Em um estudo realizado por Falk e Dierking (2010), no qual foram analisados os motivos pelos quais crianças norte-americanas fracassavam em ciências e matemática, quando comparadas a crianças de outros países, constatou-se que elas passavam apenas $5 \%$ de suas vidas em sala de aula. Além disso, havia um acúmulo de evidências indicando que a maior parte da aprendizagem de ciências ocorria fora do ambiente escolar.

Um estudo abrangente realizado pelo Harvard Research Family Project (FINDINGS..., 2007), nos Estados Unidos, analisou quarenta anos de resultados acumulados de pesquisas e demonstrou que o acesso às oportunidades complementares ou extraescolares de aprendizagem era o melhor indicador na previsão do sucesso na aprendizagem e desempenho escolar dos estudantes. O estudo também indicou que crianças em situação de vulnerabilidade social e em desvantagem econômica têm menos acesso a essas oportunidades.

No Brasil, o baixo desempenho dos alunos em ciências e matemática, comparado a outros países que fazem parte do Programa Internacional de Avaliação de Estudantes (PISA), corrobora esses resultados. De acordo com o relatório de 2015 , deste programa, menos de $1 \%$ de jovens brasileiros do sexo masculino e apenas $0,5 \%$ do de sexo feminino estavam entre os alunos com rendimento mais elevado em ciências, em contraste com os percentuais de $8,9 \%$ e $6,5 \%$ respectivamente observados em outros países participantes. Além disso, o valor gasto pelo Brasil por aluno, entre 6 e 15 anos de idade, foi o equivalente a $42 \%$ do registrado pelos outros países. O relatório também ressalta que, na época, havia um alto percentual de alunos no Brasil em camadas desfavorecidas, sendo que $43 \%$ dos alunos estavam entre os $20 \%$ mais desfavorecidos na escala internacional de níveis socioeconômicos do PISA. Outro fator importante registrado foi que a parcela de pais de alunos com escolaridade de nível superior foi menor que 15\%, uma taxa bem inferior à média de $37 \%$ observada entre os outros países (OECD, 2016).

Esses dados indicam que o baixo desempenho em ciências dos estudantes brasileiros se deve à situação de desigualdade social e à baixa escolaridade de seus responsáveis, o que, entre outros fatores, tende a reduzir o acesso às atividades extraescolares pela via familiar. $O$ investimento insuficiente pelo governo por aluno, por outro lado, contribui para a redução da qualidade do ensino, como também pode diminuir o acesso a essas oportunidades como, por exemplo, a visita a museus e outros equipamentos culturais, por meio da escola.

Muitos jovens estudantes de escolas públicas visitam museus apenas com a escola, como apontam os resultados da pesquisa feita por Cazelli (2005). A autora conclui que a escola tem um papel equalizador, possibilitando que alunos da rede pública de ensino visitem diversos tipos de museus, o que é de grande importância para esses jovens cujas famílias têm baixo capital cultural (CAZELLI, 2005).

Dessa forma, fica evidente que é de grande relevância a relação entre o museu e a escola. Partindo do contexto em que as escolas costumam visitar os museus com certa frequência, é necessário compreender que eles têm potencial de serem muito mais que uma simples complementação curricular da escola. Os museus podem proporcionar experiências com objetos que podem gerar curiosidade, motivação e questionamentos por parte dos alunos. 
Os museus há muito tempo deixaram de ser pensados como meros locais de armazenamento de artefatos; atualmente, as pessoas enxergam os museus como locais de lazer, entretenimento e educação. Para Marandino (2005), os museus de ciência podem ser considerados espaços educacionais, pois as experiências neles vivenciadas se projetam para além do deleite e da diversão.

Programas e projetos educativos são gerados, com base em modelos sociais e culturais. Seleções de parte da cultura produzida são realizadas com o intuito de torná-la acessível ao visitante. Como em qualquer organização educacional, processos de recontextualização da cultura mais ampla se processam possibilitando a socialização dos saberes acumulados. (MARANDINO, 2005, p. 165).

No entanto, a autora ressalta que existem especificidades nos processos educacionais que ocorrem nessas instituições. Van-Präet e Poucet (1989 apud MARANDINO, 2005, p. 165) relacionam a especificidade dos museus com o fato de a exposição ser uma mídia diferente da escola e de outras mídias. Nos museus, há a questão da brevidade do tempo que, embora seja essencial à comunicação, impõe um desafio ao processo educativo. Isso fica evidente quando se leva em consideração o curto intervalo de tempo que o visitante dedica a cada objeto ou tema, ao longo de uma visita, que pode ser única. Diferente da escola, que é um local fechado com poucos estímulos e liberdade de escolha, o museu tem um trajeto aberto, onde o visitante é voluntário e cativado pelos aspectos da exposição. Além disso, o discurso museal se apoia nos objetos, os quais são fonte de interatividade e riqueza (MARANDINO, 2005).

Köptcke (2002) assinala que a relação entre o museu e a educação formal se estabeleceu na história de forma complexa. Surge a partir da metade do século 20, quando havia uma coexistência de diferentes tipos de relação entre instituições de ensino formal e museus (coabitação, colaboração, complementaridade), as quais dependiam das características da instituição e dos interesses políticos em jogo. A autora defende que essa relação deve ser entendida como uma parceria feita de forma contextualizada, pelos atores sociais e dentro da dinâmica sociorrelacional sob a qual se desenvolve.

Para tal, é necessário que os museus façam estudos para compreender melhor esse público particular e os motivos pelos quais as escolas escolhem fazer uma visita ao museu ou não. É essencial que realizem estudos sobre os interesses e as preferências desse público, além disso, também é importante conhecer o não público, que compreende as pessoas ou instituições que ainda não visitaram o museu, para que este possa adotar estratégias para atrair esses grupos. Segundo Schäfer (1996), é preciso compreender algumas questões para que os museus possam traçar estratégias básicas para atrair este público, tais como: "Quais são as principais fontes de informação? Onde estão os seus campos de interesse? O que eles sabem sobre os museus? Que opiniões eles possuem sobre exposições e museus? Quais são as melhores maneiras de efetivar não-visitantes?" (SCHÄFER, 1996, p. 195, tradução nossa).

Segundo Cazelli e Coimbra (2012), as pesquisas em museus têm que lidar com o desafio da heterogeneidade de sua audiência, pois, com o estímulo da aproximação da sociedade com os museus, que acontece a partir da segunda metade do século 20, houve uma mudança no público esperado por essas instituições. Nesse sentido, os autores destacam a importância de dialogar com as múltiplas audiências e ao mesmo tempo de ampliar as representações sociais e culturais nos espaços museológicos. Para os autores, o público 
de museus é visto como um grupo em construção, podendo ser composto por segmentos sociais distintos, em um dado período.

Cazelli e Coimbra (2012) apontam que o Museu de Astronomia e Ciências Afins adota uma perspectiva baseada no conceito de autonomia do visitante sobre a decisão da visita, para delimitar, compreender e orientar suas ações de divulgação e popularização da ciência. O museu considera que seus visitantes podem ser agrupados em três tipos de audiência com graus decrescentes de autonomia: audiência de visitação espontânea, audiência de visitação programada e a audiência de visitação estimulada.

Octobre (2007 apud KÖPTCKE, 2012) apresenta uma organização de estudos de público relacionando objetivos e perguntas com diferentes tipos de público-alvo. Com relação ao público-alvo:

\begin{abstract}
[...] foram identificados quatro interlocutores para os quais os estudos costumam voltar-se: os efetivos visitantes das instituições culturais, ou seja, o público ou praticante; os grupos que por suas características sociais e culturais assemelhamse àqueles que visitam museus e constituem um público potencial a conquistar e o 'não público', ou seja, aqueles que se diferenciam dos potenciais visitantes e dos praticantes efetivos em seu perfil sociocultural e demonstram pouco ou nenhum interesse ou familiaridade quando indagados a respeito dessas instituições. Finalmente, a população de referência que representa o universo a partir da qual se podem construir parâmetros de observação dos comportamentos estudados. Dependendo do alvo, os objetivos variam. (OCTOBRE, 2007, p. 96-97 apud KÖPTCKE, 2012, p. 216).
\end{abstract}

As escolas podem ser classificadas como público potencial de acordo com a organização de Octobre (2007 apud KÖPTCKE, 2012) e como uma audiência de visitação programada, segundo a perspectiva citada por Cazelli e Coimbra (2012), além de desempenharem, no Brasil, um papel central no acesso de jovens socialmente desfavorecidos aos museus e centros culturais. Cazelli (2005) ressalta que, para os alunos da rede municipal, a escola é um contexto muito importante, não só para promover o acesso, mas garantir um número maior de museus visitados, visto que, muitas das vezes, esses jovens residem em comunidades distantes da maioria dessas instituições e, por terem baixo poder aquisitivo e capital cultural, dificilmente visitariam esses locais de outra forma. Assim sendo, esses jovens, por meio da escola, conseguem realizar uma visita de qualidade a diferentes tipos de museus, com a mediação dos educadores dessas instituições.

Nesse sentido, este artigo relata uma pesquisa que buscou entender as razões pelas quais escolas públicas municipais localizadas em bairros próximos da Fiocruz ainda não haviam visitado o Museu da Vida, dada a importância da apropriação do conhecimento científico para a vida das pessoas e o papel de destaque dessa instituição na educação não formal e na divulgação da ciência, tecnologia e saúde na cidade do Rio de Janeiro.

\title{
Metodologia
}

Esta é uma pesquisa com abordagem qualitativa, cujo objetivo fundamental é o estudo e a análise das experiências vividas dentro do seu ambiente natural (GODOY, 1995). A população estudada foi composta por escolas municipais de ensino fundamental do município do Rio de Janeiro situadas nas proximidades do Museu da Vida. 


\section{Contexto da pesquisa}

Fundado em maio de 1999, o Museu da Vida é um importante museu de ciência localizado dentro da Fundação Oswaldo Cruz (Fiocruz), no bairro de Manguinhos, Zona Norte do Rio de Janeiro, uma área pobre em equipamentos culturais no município. Melo e Peres (2005) mostraram em seu estudo a desigualdade existente na distribuição de equipamentos culturais no Rio de Janeiro, sendo que apenas 13,6\% estão localizados nas áreas onde ficam localizadas as escolas desta pesquisa (Penha, Ramos, Brás de Pina, Olaria e Penha Circular). Esse dado reforça a importância desse Museu para essa região que tanto carece de espaços culturais.

De acordo com Rocha (2008), os espaços destinados à visita do Museu da Vida recebem diariamente um público variado, como jovens, idosos, famílias, turistas e grupos escolares. Segundo a autora, o Museu valoriza a relação com a educação formal e apresenta projetos e programas que vão além da abertura das portas do museu à escola.

Nesse sentido, o Núcleo de Estudos de Público e Avaliação em Museus (Nepam) realizou um estudo sobre as escolas visitantes do Museu da Vida, no período de 1999 a 2008, cuja proposta foi identificar a abrangência geográfica e a participação do público escolar na visitação ao Museu da Vida (DAMICO; MANO; KÖPTCKE, 2009).

O estudo revelou que o público escolar representou $83 \%$ do total de atendimentos do Circuito de Visitação nos seus nove anos iniciais, sendo a faixa de 10 a 15 anos (58\%), correspondente aos alunos do primeiro ciclo do ensino básico, a maior frequência registrada. Dentre as visitas escolares, $45 \%$ foram realizadas por escolas públicas, com $27 \%$ desse quantitativo correspondendo às escolas municipais, $16 \%$ de estaduais e $2 \%$ de federais (DAMICO; MANO; KÖPTCKE, 2009).

Gráfico 1 - Distribuição relativa das escolas que visitaram o Museu da Vida localizadas na Zona Norte

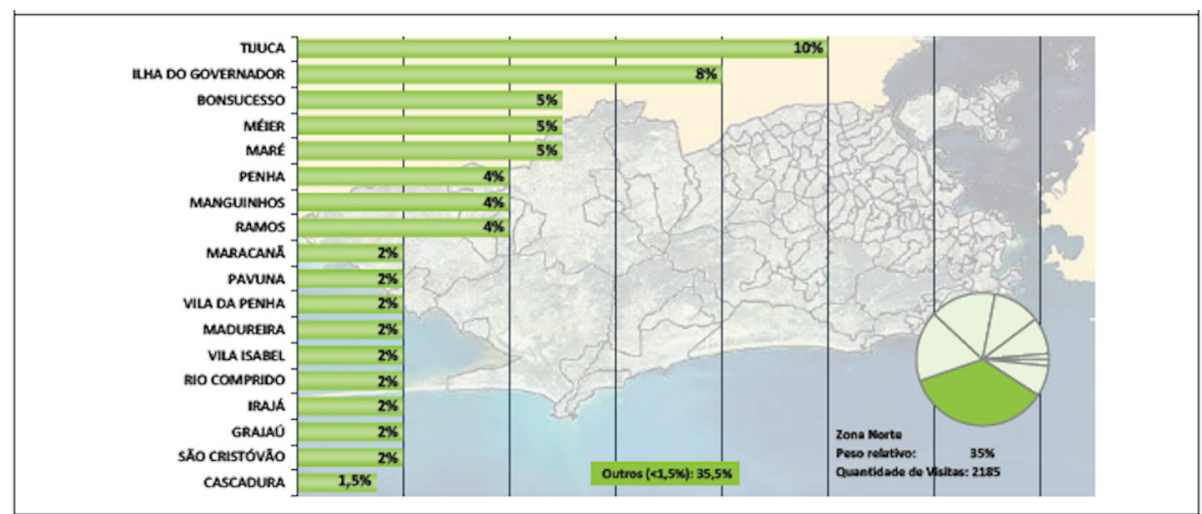

Fonte: Damico, Mano e Köptcke (2009, p. 23).

No Gráfico 1 são apresentadas as regiões de procedência das escolas que visitaram o Museu, segundo Damico, Mano e Köptcke (2009). Das frequências observadas, 35\% correspondiam a bairros da Zona Norte do Rio de Janeiro, seguidas pelas dos bairros da Zona Oeste, que representavam, cumulativamente, $17 \%$ da amostra. Com relação às escolas dos bairros da Zona Norte, as localizadas na Tijuca apresentaram o maior percentual, com 10,4\%, seguida das localizadas na Ilha do Governador, com 7,6\%. A classe "outros", em virtude da grande quantidade de bairros (60) que ficaram abaixo da linha de corte de 1,5\%, acabou concentrando o elevado percentual de $36,2 \%$. 
Um estudo mais recente realizado pelo Nepam revelou que esse cenário sofreu algumas mudanças, como a redução para $40 \%$ na participação das escolas públicas na visitação agendada e a composição etária do público escolar visitante, no qual as faixas de 7 a 12 anos e de 15 a 18 anos foram predominantes e apresentaram frequências próximas de $44 \%$ e $42 \%$ respectivamente (MANO et al., 2015).

\section{Amostra}

O universo pesquisado foi delimitado a partir de uma consulta à base de dados de agendamentos de visitas ao Museu da Vida, no período desde a sua inauguração, em 1999, até 2017 , de onde se obtiveram os dados sobre as escolas visitantes, provenientes dos bairros situados nas proximidades da Fundação Oswaldo Cruz. Foi também realizado um levantamento das escolas subordinadas à $4^{\text {a }}$ Coordenadoria Regional de Educação (CRE), órgão governamental que coordena as escolas dos bairros próximos à Fiocruz. A partir do cruzamento da consulta à base de dados com esse levantamento das escolas da $4^{\mathrm{a}} \mathrm{CRE}$, foi definida a amostra estudada, composta de 14 escolas públicas municipais que ainda não haviam realizado visitas ao Museu da Vida, localizadas em bairros como: Penha, Ramos, Olaria, Penha Circular e Brás de Pina. Para evitar a exposição das escolas, foi criado um código para cada uma no Quadro 1, demonstrando os bairros onde estão localizadas.

Quadro 1 - Escolas participantes da pesquisa e os bairros onde estão localizadas

\begin{tabular}{|l|l|}
\hline Nome da Escola & \multicolumn{1}{|c|}{ Bairro } \\
\hline Escola 01 & Penha \\
\hline Escola 02 & Ramos \\
\hline Escola 03 & Ramos \\
\hline Escola 04 & Olaria \\
\hline Escola 05 & Olaria \\
\hline Escola 06 & Penha \\
\hline Escola 07 & Penha \\
\hline Escola 08 & Penha \\
\hline Escola 09 & Penha Circular \\
\hline Escola 10 & Penha Circular \\
\hline Escola 11 & Brás de Pina \\
\hline Escola 12 & Brás de Pina \\
\hline Escola 13 & Olaria \\
\hline Escola 14 & Olaria \\
\hline
\end{tabular}

Fonte: Cabral (2018).

\section{Instrumento da pesquisa}

O instrumento de pesquisa foi um questionário com 42 questões aplicado pela pesquisadora a 21 profissionais das escolas selecionadas. Os sujeitos da pesquisa foram escolhidos com base em sua participação autodeclarada no processo de seleção das atividades complementares desenvolvidas pelas escolas que compuseram a amostra. Eles ocupavam os seguintes cargos: equipe da direção, professores de ciências e coordenadores pedagógicos (Quadro 2). O questionário continha questões abertas e fechadas e era dividido em sete seções, de acordo com a temática das perguntas, sendo que seis delas se destinavam 
a conhecer melhor os sujeitos da pesquisa, seu perfil, interesses e hábitos culturais e de lazer e a última visava compreender os processos decisórios relativos às atividades complementares desenvolvidas pelas escolas.

A primeira seção, Sobre você, continha questões relacionadas ao perfil socioeconômico do sujeito da pesquisa, como sexo, idade, escolaridade e indicadores socioeconômicos. Na segunda seção, intitulada Inserção profissional, foram abordados aspectos da relação profissional do indivíduo com a escola. Na seção Seu interesse por ciência e tecnologia, buscouse avaliar o grau de interesse do sujeito por assuntos relacionados a ciência e tecnologia. Essa seção só foi aplicada àqueles cuja formação/atuação não era em áreas relacionadas diretamente a esses temas, pois se partiu do pressuposto de que os profissionais com formação na área científica se interessam por ciência. A seção Sobre seus hábitos culturais e de lazer visava conhecer os hábitos de leitura, a frequência a museus e teatros, etc. e as atividades de lazer preferidas pelos indivíduos. Na seção Associações com as ideias de museu, buscou-se compreender que ideias os respondentes associavam aos museus, além de investigar quais museus de ciências eles já haviam visitado. A seção Sobre as visitas ao Museu da Vida buscava investigar se os participantes da pesquisa já haviam feito alguma visita ao Museu e, caso tivessem feito, como se deram essas visitas. A seção final Atividades complementares continha questões cujo objetivo era esclarecer como ocorriam as escolhas das atividades complementares realizadas pelas escolas.

O questionário continha também cinco perguntas abertas visando aprofundar o conhecimento sobre os processos decisórios relativos às atividades complementares. As respostas dessas questões foram anotadas pela pesquisadora durante a aplicação do questionário, na medida em que as escolas não autorizaram a realização de gravação.

No presente artigo foram analisadas as respostas às seções Sobre Você, Sobre seus hábitos culturais e de lazer, Atividades complementares, e as perguntas abertas.

Quadro 2 - Cargos exercidos pelos respondentes nas escolas participantes da pesquisa

\begin{tabular}{|l|c|}
\hline \multicolumn{1}{|c|}{ Cargo na escola } & Respondentes $\left(\mathbf{n}^{\circ}\right)$ \\
\hline Diretor(a) & 4 \\
\hline Diretor(a) adjunto(a) & 7 \\
\hline Coordenador(a) pedagógico(a) & 5 \\
\hline Professor(a) & 5 \\
\hline Total & $\mathbf{2 1}$ \\
\hline
\end{tabular}

Fonte: Cabral (2018).

As respostas às questões fechadas foram tabuladas no software Microsoft Excel ${ }^{\circledR}$ e feita a análise estatística descritiva. As respostas às questões abertas foram analisadas pelo método do Discurso do Sujeito Coletivo (DSC) (LEFÈVRE; LEFÈVRE, 2012). Essa análise consiste em uma interpretação qualiquantitativa que apresenta as categorias e expressões-chave presentes nos discursos dos entrevistados como discursos únicos. Foi também analisada a intensidade desses discursos pela indicação do número de pessoas que o compartilharam. 


\section{Resultados e Discussão}

\section{Perfil socioeconômico}

Dezoito respondentes eram do sexo feminino, sendo que oito deles estavam na faixa etária dos 40 a 49 anos, e sete na de 30 aos 39 anos. No quesito escolaridade, 19 tinham pósgraduação, sendo que, deste total de respondentes, cinco tinham Mestrado e apenas um Doutorado.

Quanto à renda mensal familiar declarada, a faixa entre mais de três e dez salários mínimos (R\$ 2.812,00 a $\mathrm{R} \$ 9.370,00)$ foi apresentada por 14 respondentes, e cinco respondentes declararam sua renda mensal na faixa acima de 15 salários mínimos (R\$ $14.055,00)$.

O indicador de renda mensal familiar declarada pela maioria dos respondentes ( $R \$$ $2.812,00$ a R\$ 9.370,00) está próximo ou superior à média de rendimentos mensal per capita apresentadas pelo Instituto Brasileiro de Geografia e Estatística (IBGE, 2017), de $R \$ 1.445,00$ para a população do Rio de Janeiro, levando em consideração a quantidade de pessoas que residem na mesma casa.

\section{Hábitos culturais e de lazer}

Sobre os hábitos culturais e de lazer, é possível observar que 15 indivíduos declararam ter o hábito de ler jornais ou revistas (digitais ou impressas) com frequência e também 15 leram algum livro no último ano, sendo que nove leram mais de dois livros. Vinte dos respondentes foram mais de duas vezes ao teatro e visitaram mais de três museus.

Quanto aos museus visitados, 15 pessoas declararam ter visitado o Museu Nacional da Universidade Federal do Rio de Janeiro (UFRJ). Nesse quesito, muitos dos respondentes escolheram mais de uma opção de resposta, indicando que eles visitaram os museus mais de uma vez. Catorze declararam que foram com a escola e com a família e quatro com a escola e com outros.

O hábito de leitura de livros dos integrantes desta pesquisa se apresentou muito superior ao dos cariocas, segundo o relatório sobre os hábitos culturais dos cariocas (LEIVA, 2016), em que 64\% dos entrevistados apresentaram esse costume de ler livros. É possível observar um contraste nos quesitos ir ao teatro e a museus, que aparecem com frequências de $37 \%$ e $34 \%$, respectivamente, nos hábitos culturais dos cariocas. De acordo com o relatório, o costume de frequentar teatros e museus é maior entre pessoas que apresentam renda familiar mensal superior a dez salários mínimos, podendo ser uma das razões da maioria dos respondentes já terem ido a mais de duas peças de teatro e a mais de três museus, visto que um terço (7) dos respondentes se situam nessa faixa de renda.

Os resultados revelam que os respondentes têm o hábito de frequentar museus e se dedicam também a outras práticas culturais, como ler e ir ao teatro, no âmbito de sua vida pessoal. Além disso, revelam que frequentaram museus com suas escolas. Dessa forma, fica claro que reconhecem a importância e o valor dessas atividades tanto para si, como para seus alunos. 


\section{Atividades complementares ao currículo escolar}

Sobre as atividades complementares, 18 participantes da pesquisa responderam que as escolas realizam pelo menos uma atividade por ano. O número de atividades complementares realizadas pelas escolas, em ordem de frequência, foi: mais de cinco atividades (7), uma atividade (5), de quatro a cinco atividades (5) e, por fim, de duas a três atividades (4).

Esse resultado está relacionado às atividades realizadas dentro da escola, como feiras culturais e de ciências, como, também, com instituições que vão até as escolas para ministrar palestras, ou seja, atividades que não implicam deslocamento ou demandam maiores recursos. As atividades realizadas fora da escola acontecem, na maioria das vezes, quando o transporte é ofertado por terceiros, pois a escola não tem como arcar com esse custo. O processo de seleção dessas atividades, de acordo com a opinião de 18 respondentes, acontece de forma coletiva.

De acordo com 20 respondentes, as visitas aos museus foram as atividades externas mais realizadas pelas escolas no último ano. Nos últimos três anos, nove das escolas visitaram de dois a três museus, dos quais 14 respondentes disseram que eram museus relacionados à ciência e tecnologia. Seis participantes da pesquisa declararam ter visitado o Museu do Amanhã e outros seis o Planetário e Museu do Universo, que foram os museus de ciência mais citados nas respostas. Tal resultado pode estar relacionado ao fato de que essas instituições pertencem ou têm vínculos com a Prefeitura do Rio de Janeiro, o que facilitaria o acesso das escolas municipais.

\section{Fatores que influenciam a seleção das atividades complementares}

Os resultados da análise pelo método do Discurso do Sujeito Coletivo (DSC) das respostas às perguntas abertas, relativas à seleção das Atividades complementares pelos profissionais das escolas, são apresentadas a seguir.

A questão O queélevado em consideração no processo decisório? produziu respostas cuja análise geraram três DSCs distribuídos em três categorias relativas aos fatores considerados mais importantes para a tomada de decisão. Nessas categorias foram apontadas as principais motivações determinantes das escolhas das atividades complementares. A primeira diz respeito aos aspectos educativos e lúdicos das atividades, a segunda aborda questões de natureza prática como custos e transporte, e a terceira aponta interesses de natureza externa e o uso da atividade de forma excludente como modo de premiação.

Categoria A: Aspecto educativo e lúdico (intensidade: 16)

Categoria B: Custos e meio de locomoção (intensidade: 9)

Categoria C: Interesses externos (intensidade: 2)

\section{Categoria A: aspecto educativo e lúdico}

DSC.1: Normalmente, é o aspecto educativo e lúdico, para que os alunos se divirtam e aprendam ao mesmo tempo e possam sair da rotina de sala de aula. Tem que haver também conteúdo relacionado às disciplinas dadas em sala, além da sua aplicabilidade para os alunos mais tarde. Deve estar também dentro do projeto pedagógico da escola e de acordo com o centro de interesses dos alunos. 
Nesse discurso, o aspecto educativo, a ludicidade, a diversão, e os conteúdos abordados são aspectos importantes para a escolha da atividade a ser realizada. Em seu estudo, Silva e Soares (2011) observaram que parte dos professores de sua pesquisa justificou a visita ao museu de ciências por ser um ambiente que desperta o prazer em aprender e apontou a relação entre divertimento e aprendizagem nesse tipo de museu. Na opinião desses professores, os alunos vão ao museu para aprender e se divertir ao mesmo tempo, não havendo conflito entre essas duas questões.

Também é possível observar nesse discurso que a escolha das atividades deve estar inserida dentro do projeto pedagógico da escola, que é um instrumento de construção coletiva, com a função de apresentar as finalidades, concepções e diretrizes do funcionamento da escola, e orienta todas as outras ações escolares.

Além disso, a inclusão do centro de interesses dos alunos é ressaltada como um fator para ser levado em consideração no processo de escolha das atividades. O centro de interesse é um método educacional desenvolvido pelo educador belga Ovid Decroly, cujas necessidades fisiológicas, psicológicas e sociais do aluno são levadas em consideração na construção do currículo, partindo da ideia da globalização do ensino para romper com a rigidez dos programas escolares. Dessa forma, os centros de interesses estão relacionados aos interesses particulares dos alunos, nos quais o conhecimento necessita ter uma significação para a criança e não ser apenas distribuído em matérias.

\section{Categoria B: custos e meio de locomoção}

DSC.2: A disponibilidade de transporte principalmente. De tudo um pouco, o custo, porque é o que acaba fazendo ir ou não ao local. A questão se o local oferece ônibus, as crianças nem sempre têm como custear a passagem, então é necessário o transporte gratuito. Quando surge uma oportunidade e é disponibilizado o transporte, a escola aproveita a oportunidade.

A disponibilidade de transporte e o custo envolvido na realização da atividade complementar aparecem nesse discurso como fatores cruciais a serem levados em consideração no processo decisório de escolha dessas atividades. Por se tratar de escolas públicas, os alunos geralmente não apresentam condições financeiras para acessar esse tipo de atividades fora da escola, visto que os espaços visitados são, na maioria das vezes, distantes de suas casas. Além disso, a escola dificilmente consegue recursos, além do seu orçamento anual, para financiar essas atividades. Fica evidente, então, que as escolas sofrem uma restrição de recursos, dificultando que elas desenvolvam programas de atividades complementares compatíveis com as necessidades e os interesses das comunidades em que estão inseridas.

No entanto, quando esses recursos são disponibilizados, eles são alocados de forma arbitrária, sem a participação da comunidade escolar, por meio de projetos criados ou apoiados pela Secretaria Municipal de Educação (SME) e $4^{\mathrm{a}} \mathrm{CRE}$, que, por muitas vezes, apresentam interesses políticos envolvidos, como evidenciado no Discurso do Sujeito Coletivo 3 (DSC.3). Essas questões acabam gerando frustração dentro da escola, pois a comunidade escolar fica impedida de realizar as atividades que Ihe mais interessam. Cabe à Prefeitura do Rio de Janeiro, mais especificamente à SME, fornecer recursos suficientes para a escola manter seu funcionamento normal, como também para a realização de atividades complementares que são essenciais à formação dos alunos. 
Os projetos apoiados pelas instâncias superiores às escolas são importantes, porém, deveriam ser um complemento aos que são propostos pela própria comunidade escolar.

\section{Categoria C: interesses externos}

DSC.3: Existem interesses políticos da $4^{a}$ CRE na escolha desses passeios além do aspecto educativo, onde a escola recebe o passeio pronto da coordenadoria (com ônibus com quantidade de assentos limitada) tornando-o um prêmio para os alunos mais interessados.

Nesse discurso, está evidente que a escola tem pouca participação no processo de escolha das atividades. Onde a 4a Coordenadoria Regional de Educação (CRE) escolhe quais atividades serão realizadas de acordo com seus interesses e entrega à escola o roteiro pronto, junto com o transporte. No entanto, o transporte ofertado não consegue abarcar todos os alunos, então a atividade acaba se tornando um prêmio para os alunos que se mostram mais interessados na sala de aula. Ficou claro que essas situações causam desconforto aos respondentes; selecionar alguns alunos acaba causando a exclusão de outros. Para eles, o ideal seria que todos os alunos pudessem aproveitar esse tipo de atividade. Assim, é fundamental que todos os alunos sejam contemplados por essas oportunidades para que, de alguma forma, tenham acesso aos diferentes tipos de equipamentos culturais.

Em resposta a essa questão, os discursos dos professores (3) se apresentaram dentro da categoria A, cujo aspecto educativo é o principal fator levado em consideração no processo de escolha das atividades. A equipe diretiva (11) e a coordenação pedagógica (5) apresentaram predominantemente discursos dentro da categoria $A$ e $B$, sendo este último relacionado ao custo e à oferta de transporte. Dois professores proferiram o discurso inserido na categoria $C$, onde os interesses da $4^{a}$ CRE são fatores cruciais na escolha das atividades. Nesse sentido, é possível observar que os professores atentam mais à parte pedagógica na decisão das atividades complementares a serem realizadas pelas escolas, no entanto, apresentam também certa crítica ao controle da $4^{\text {a }}$ CRE sobre essa escolha. Já os coordenadores e a equipe diretiva, além de se importarem com questões pedagógicas, preocupam-se também com a questão financeira para a realização dessas atividades, afinal, são os diretores que gerem a verba da escola, e eles também fazem críticas à dependência da $4^{\mathrm{a}} \mathrm{CRE}$.

$\mathrm{Na}$ questão Existe algum fator que dificulte a realização de atividades complementares realizadas fora da escola? Se sim, qual(is) é(são) esse(s) fator(es)?, foram emitidos dois discursos distintos classificados em duas categorias. Na primeira categoria, foi expresso um discurso reiterando a falta de meios de locomoção e os custos envolvidos no deslocamento dos alunos, como impedimentos para a realização de atividades complementares, neste caso, fora da escola. Na segunda categoria, o discurso apontou a violência urbana como um fator que gera dificuldades à realização dessas atividades que, entretanto, não pode ser contornado.

Categoria A: Meio de locomoção (intensidade: 21)

Categoria B: Questão da violência (intensidade: 4) 


\section{Categoria A: Meio de locomoção}

DSC.4: O que dificulta é o transporte, falta de verba para o ônibus e questão de verba reduzida pela escola, pois normalmente os passeios são gratuitos. Até o Pão de Açúcar é de graça, mas falta o ônibus. Portanto, quando fazemos passeios, os alunos custeiam a passagem, porque a prefeitura não disponibiliza ônibus com gratuidade plena. Fora isso, os pais são tranquilos em autorizar e a alimentação sempre se dá um jeito, até mesmo quando não fornecem lanche, a escola consegue. Se a pessoa oferecer transporte, levamos para qualquer lugar. Porém, não podemos levar a escola toda e temos que selecionar algumas turmas para ir ao passeio. Além disso, precisamos do calendário compatível, o resto a gente consegue, porque vontade todo mundo tem.

A questão do transporte e a verba para custeá-lo novamente surgem como fatores determinantes à realização ou não de atividades complementares. É evidente a vontade das escolas de realizarem mais atividades desse tipo, porém elas ficam impossibilitadas por não conseguirem o transporte gratuito para locomover os alunos a outros lugares. As escolas têm verba reduzida e raramente sobra para custear esse tipo de atividade.

Outra questão é a de não poder levar todos os alunos, sendo apenas alguns alunos selecionados para participarem da atividade porque não existe transporte suficiente para todos. Em alguns casos, os alunos conseguem custear parte da passagem porque a prefeitura não oferece ônibus com gratuidade plena, o que não deixa de ser um problema, pelo fato de ser uma instituição pública cobrando a passagem dos alunos e sempre gerar um desconforto, na medida em que exacerba um quadro já grave de desigualdades. Alguns professores revelaram que, quando o local onde a atividade seria realizada era perto da escola, eles se arriscavam levando os alunos a pé ou pedindo carona nos ônibus comuns. Isso mostra a vontade dos professores de proporcionar novos tipos de experiência a seus alunos, por meio de atividades fora da escola, o que é constantemente dificultado pela falta de recursos.

\section{Categoria B: questão da violência}

DSC.5: Tem o caso da violência, a situação de confronto na comunidade próxima da Fiocruz, o que causa preocupação da escola com a situação de segurança dos alunos, mas isso não tem como contornar. Portanto, raramente existem pais que não liberam os filhos por medo.

Algumas escolas expressam uma preocupação com a violência em comunidades próximas ao Museu da Vida, gerando um receio de realizar uma visita ao local. No entanto, esse não parece ser um fator crucial que impeça as escolas de visitar o Museu, pois raramente os pais impedem seus filhos de participarem dessa atividade. A violência tem se tornado algo comum no Rio de Janeiro, onde até as escolas estão tentando se adaptar.

Os coordenadores (5), os professores (4) e os diretores (9) em sua maioria expressaram um discurso dentro da categoria $A$, onde a falta de transporte é o principal fator que dificulta a realização de atividades complementares fora da escola. Dois diretores emitiram um discurso inserido na categoria B, falando especificamente do Museu da Vida, revelando uma preocupação com a situação de violência dentro das comunidades do entorno do Museu.

Os discursos expressos nessa questão estão próximos dos dados apresentados na pesquisa feita por Mano et al. (2017), apontando que os principais fatores que dificultam a visita a museus são a violência urbana (14\%) e a dificuldade de acesso: 
transporte, estacionamento, etc. (27\%), indicando que esses fatores não estão restritos apenas às escolas, lembrando que o estudo realizado por Mano et al. (2017) foi feito com visitantes espontâneos, ou seja, escolas não faziam parte do seu corpus.

Alguns dados desta pesquisa corroboram com os dados da tese de Cazelli (2005), que relacionou as dificuldades relatadas por escolas para visitas a museus, comparando as instituições da rede municipal com as da rede privada. Os problemas mais relatados pelas escolas municipais, segundo a pesquisa da autora, foram o transporte, em primeiro lugar, seguido da dificuldade em conseguir recursos com os pais para despesas relacionadas à visita, a marcação da visita com a instituição no período desejado e superar a preocupação relativa à violência urbana. O transporte e a questão da violência, como na pesquisa de Cazelli (2005), apareceram também nesta pesquisa como uma dificuldade para a realização de atividades complementares fora da escola. Também foi expresso nos discursos a questão do calendário compatível, o que pode estar inserido dentro da dificuldade na marcação de visitas com as instituições no período desejado pelas escolas.

Com esses discursos, podemos observar que todas as escolas pesquisadas tinham o hábito de visitar equipamentos culturais, como museus, e não o faziam com mais frequência por falta de transporte e verba, os quais foram os principais fatores levantados pelos respondentes como dificuldades para a realização dessas atividades.

Outro fator importante que dificulta o acesso aos equipamentos culturais são as desigualdades socioespaciais na distribuição dos equipamentos culturais na cidade do Rio de Janeiro. Segundo o estudo feito por Melo e Peres (2005), onde foi considerada a distribuição de seis tipos de equipamentos culturais (bibliotecas, museus, centros culturais, parques e florestas, teatros e cinemas), a área de planejamento 3, na qual estão inseridos os bairros das escolas desta pesquisa (Ramos, Penha, Olaria, Penha Circular, Brás de Pina), apresenta apenas $13,6 \%$ desses equipamentos situados em suas áreas, enquanto a área de planejamento 2 , que tem como alguns de seus bairros Botafogo e Copacabana, tem $42 \%$ deles. Este estudo mostra que a desigualdade existente na distribuição desses equipamentos culturais no Rio de Janeiro dificulta e até inviabiliza o acesso de pessoas de áreas carentes a eles. Portanto, para esses grupos, a escola continua sendo o principal meio de acesso a diferentes tipos de equipamentos culturais.

\section{Considerações Finais}

A importância da ciência e tecnologia atualmente é incontestável e, por isso, Moreira (2006) enfatiza como é fundamental ao cidadão do mundo contemporâneo compreender assuntos relacionados a esses temas, seus principais resultados, riscos, métodos utilizados e, também, os interesses econômicos e políticos envolvidos. Para o autor, o conhecimento básico sobre a ciência e seu funcionamento é um dos aspectos da inclusão social, pois proporciona ao indivíduo maior compreensão da cultura e do mundo que o cerca e possibilita que atue politicamente com conhecimento de causa. O autor também pontua que a educação científica no país não é feita de forma abrangente, não tem qualidade no ensino escolar e ressalta a importância da educação não formal e da divulgação científica para a mudança desse cenário. Dessa forma, os museus de ciência apresentam um papel de destaque, como espaços de divulgação científica, contribuindo ao enriquecimento do conhecimento científico da sociedade. 
Neste estudo, observamos que o perfil socioeconômico dos profissionais envolvidos na seleção das atividades complementares realizadas pelas escolas era compatível com o dos frequentadores de museus em geral e do Museu da Vida, em particular. A análise de seus hábitos de consumo cultural também revelou que o grupo costumava frequentar museus tanto com as escolas em que trabalhavam, como na vida privada com suas famílias e amigos, e alguns deles já haviam visitado o Museu da Vida mais de uma vez. Assim, pudemos concluir que a ausência de visitas dessas escolas ao Museu da Vida não decorreu de uma rejeição ou desinteresse por parte dos profissionais pesquisados. Na verdade, apesar de as escolas, em função de restrições orçamentárias, privilegiarem a realização de atividades complementares dentro do próprio ambiente escolar, sempre que podiam desenvolver atividades externas preferiam visitar museus.

Quanto aos métodos de seleção, a escolha era feita, sempre que possível, de forma democrática envolvendo toda a comunidade escolar (equipe diretiva, professores, coordenadores pedagógicos e alunos). Os critérios adotados pelos profissionais participantes à seleção das atividades complementares eram os aspectos educativo e lúdico, assim como questões de natureza prática, como o custo envolvido e a disponibilidade de um meio de transporte para a sua realização. Também foi levantada a questão da existência de interesses políticos externos que impedem muitas vezes que a escola tenha autonomia na seleção das atividades complementares. A ausência de recursos para financiar o acesso universal dos alunos a essas atividades foi apontado como o principal fator limitante das visitas da escolas aos museus, especialmente àqueles que não têm vínculos com a administração municipal, como é o caso do Museu da Vida. A violência urbana, embora cause preocupação, não foi considerado um fator inibidor na realização das atividades extracurriculares externas.

O Museu da Vida dispõe de uma equipe de Ações Territorializadas que promove ações educativas nas escolas e viabiliza a visita delas ao Museu ofertando ônibus (Expresso da Ciência) e faz a divulgação desse serviço por meio de seu site e redes sociais, mas, ainda assim, as escolas encontram dificuldades para realizar a visita. Um possível caminho a ser seguido pelo Museu da Vida seria se aproximar mais dessas escolas, tentando aumentar a divulgação, por outros meios além dos eletrônicos, talvez ampliar a oferta de ônibus e buscar outras formas de interagir com as escolas além das que já são realizadas. O Museu da Vida é um importante museu de ciência e está localizado em uma área carente de equipamentos culturais, conferindo-lhe uma posição privilegiada para divulgar a ciência e promover a saúde nas comunidades próximas, especialmente nas escolas públicas na sua zona de influência. Por essas razões, é essencial que haja uma aproximação dessas escolas localizadas em comunidades carentes, para que possa oferecer aos alunos a oportunidade de entrar em contato com a ciência e a tecnologia. Nesse sentido, cabe destacar também a importância da visita aos museus de ciência para o enriquecimento cultural e do conhecimento científico dos alunos de escolas públicas, que não dispõem de muitas oportunidades como essas no seio das suas famílias (CAZELLI, 2005).

Entretanto, é preciso enfatizar que não são apenas os museus que devem tomar medidas para que mais escolas os visitem. O Governo deve liberar recursos para que as escolas possam realizar atividades complementares externas e visitar museus e outros equipamentos culturais, favorecendo o enriquecimento cultural e o aprendizado de seus alunos. O museu deve tomar medidas para atrair e facilitar a visitação desse público, porém, é inviável para qualquer instituição disponibilizar transporte para todas as escolas que o desejem. 
Após a realização desta pesquisa, todas as escolas que compuseram a amostra foram convidadas a visitar o Museu da Vida, com a oferta do ônibus Expresso da Ciência para trazê-las. Além disso, o Museu tem tomado medidas de aproximação com as escolas que se localizam em seu entorno, entrando em contato direto com a direção e mostrando as atividades e exposições que estão em funcionamento.

\section{Referências}

CABRAL, E. C. O público potencial escolar do museu da vida: um estudo exploratório em escolas da zona norte da cidade do Rio de Janeiro. 2018. Dissertação (Mestrado em Divulgação da Ciência, Tecnologia e Saúde) - Casa de Oswaldo Cruz, Fundação Oswaldo Cruz, Rio de Janeiro, 2018. Disponível em: https://cutt.ly/7fF01q5. Acesso em: 8 maio 2020.

CAZELLI, S. Ciência, cultura, museus, jovens e escola: quais as relações? 2005. Tese (Doutorado em Educação) - Pontifícia Universidade Católica do Rio de Janeiro, Rio de Janeiro, 2005. Disponível em: http://www.fiocruz.br/brasiliana/media/tese_sibelecazelli.pdf. Acesso em: 8 maio 2020.

CAZELLI, S.; COIMBRA, C. A. Q. Pesquisas educacionais em museus: desafios colocados por diferentes audiências. In: WORKSHOP INTERNACIONAL DE PESQUISA EM EDUCAÇÃO EM MUSEUS, 1., 2012, São Paulo. Anais [...]. São Paulo: Universidade de São Paulo, 2012. Disponível em: https://cutt. ly/IfF03qB. Acesso em: 8 maio 2020.

DAMICO, J. S.; MANO, S. M. F.; KÖPTCKE, L. S. O público escolar do Museu da Vida: origem geográfica das escolas visitantes (1999-2008). Rio de Janeiro. Fundação Oswaldo Cruz, (Cadernos Museu da Vida, 2).

FALK, J. H.; DIERKING, L. D. The 95 percent solution: school is not where most Americans learn most of their science. American Scientist, New Haven, v. 98, n. 6, p. 486-493, 2010. DOI: https://doi. org/10.1511/2010.87.486.

FINDINGS from HFRP's study of predictors of participation in out-of-school time activities: Fact sheet. Cambridge, MA: Harvard Graduate School of Education, [2007]. Disponível em: https://cutt.ly/ efF2etw. Acesso em: 8 maio 2020.

GODOY, A. S. Introdução à pesquisa qualitativa e suas possibilidades. Revista de Administração de Empresas, São Paulo, v. 35, n. 2, p. 57-63, 1995.

IBGE. Panorama Brasil. Rio de Janeiro: IBGE, [2017]. Disponível em: https://cidades.ibge.gov.br/ brasil/panorama. Acesso em: 8 maio 2020.

KÖPTCKE, L. S. Analisando a dinâmica da relação museu-educação formal. In: CADERNO do Museu da Vida: o formal e o não-formal na dimensão educativa do museu 2001/2002. Rio de Janeiro: Museu da Vida, 2002. p. 16-25.

KÖPTCKE, L. S. Público, o $X$ da questão?: a construção de uma agenda de pesquisa sobre os estudos de público no Brasil. Museologia \& Interdisciplinaridade, Brasília, v. 1, n. 1, p. 209- 235, jan./jul. 2012. Disponível em: https://cutt.ly/iff2iht. Acesso em: 8 maio 2020.

LEIVA, J. J. Cultura e esporte. In: SEMINÁRIO PERFIL CULTURAL DOS CARIOCAS, 2016. Disponível em: http://www.culturanorio.com.br. Acesso em: 8 maio 2020.

LEFÈVRE, F.; LEFÈVRE, A. M. C. Pesquisa de representação social: um enfoque qualiquantitativo: a metodologia do discurso do sujeito coletivo. Brasília: Liber, 2012.

MANO, S.; CAZELLI, S.; COSTA, A. F.; DAMICO, J. S.; SILVA, L. C.; CRUZ, W. S.; GUIMARÃES, V. F. Museus de ciências e seus visitantes: estudo Longitudinal: 2005, 2009, 2013. Rio de Janeiro: Fundação Oswaldo Cruz, 2017. Disponível em: https://cutt.ly/QfF2kJR. Acesso em: 8 maio 2020. 
MANO, S. M. F.; DAMICO, J. S.; GOUVEIA, F. C.; GUIMARÃES, V. F. O público do museu da vida (19992013). Rio de Janeiro: Fundação Oswaldo Cruz, 2015. Disponível em: https://cutt.ly/Hff2vfM. Acesso em: 9 maio 2020.

MARANDINO, M. Museus de ciências como espaços de educação. In: MUSEUS: dos gabinetes de curiosidades à museologia moderna. Belo Horizonte: Argumentum, 2005. p. 165-176.

MELO, V.; PERES, F. A cidade e o lazer: as desigualdades socioespaciais na distribuição dos equipamentos culturais na cidade do Rio de Janeiro e a construção de um indicador que oriente as ações em políticas públicas. Movimento, Porto Alegre, v. 11, n. 3, p. 127-151, 2005.

MOREIRA, I. de C. A inclusão social e a popularização da ciência e da tecnologia no Brasil. Inclusão Social, Brasília, v. 1, n. 2, p. 11-16, 2006.

OECD. Country note: Programme for International Student Sssessment (PISA): results from PISA 2015: Brasil. [Paris]: OECD, 2016. Disponível em: http://download.inep.gov.br/acoes_internacionais/ pisa/resultados/2015/pisa_2015_brazil_prt.pdf. Acesso em: 28 jun. 2018.

ROCHA, V. A contribuição da visita ao Museu da Vida para a formação de concepções sobre saúde e ambiente: uma experiência com jovens do projeto ciência e sociedade. 2008. Dissertação (Mestrado em Ensino de Biociências e Saúde) - Instituto Oswaldo Cruz, Rio de Janeiro, 2008.

SCHÄFER, H. Non-visitor research: an important addition to the unknown. Visitor Studies, London, v. 9, n. 1, 195-205, 1996.

SILVA, A. M.; SOARES, C. Agenda de professores de ciência em visitas escolares a um museu. In: REUNIÃO BIENAL DA REDE DE POPULARIZAÇÃO DA CIÊNCIA E DA TECNOLOGIA DA AMÉRICA LATINA E DO CARIBE (RedPOP), 12., 2011, Campinas. Anais. [...]. Campinas: Unicamp, 2011. p. 1-10. Disponível em: https://cutt.ly/efF0B8u. Acesso em: 8 maio 2018. 